\title{
Benefits from an autobiographical memory facilitation programme in relapsing- remitting multiple sclerosis patients: a clinical and neuroimaging study
}

Alexandra Ernst, ${ }^{1}$ Marion Sourty, ${ }^{2}$ Daniel Roquet, ${ }^{2}$ Vincent Noblet,${ }^{2}$ Daniel Gounot, ${ }^{2}$ Frédéric Blanc, ${ }^{2,3,4}$ Jérôme de Seze, ${ }^{3,4}$ Liliann Manning ${ }^{1}$

${ }^{1}$ Cognitive Neuropsychology and Physiopathology of Schizophrenia (INSERM UMR 1114), University of Strasbourg, Strasbourg, France

${ }^{2}$ ICube (CNRS UMR 7357), University of Strasbourg, Fédération de Médecine translationnelle de Strasbourg (FMTS), Strasbourg, France

${ }^{3}$ Department of Neurology and Centre Mémoire de Ressources et de Recherche (CMRR), University Hospital of Strasbourg, Strasbourg, France

${ }^{4}$ Clinical Investigation Centre (CIC, INSERM 1434), University Hospital of Strasbourg, Strasbourg, France

Corresponding author: Dr L. Manning

Psychology Department. University of Strasbourg

12, rue Goethe, 67000 Strasbourg, France

E-mail: manning@unistra.fr 


\begin{abstract}
While the efficacy of mental visual imagery (MVI) to alleviate autobiographical memory (AM) impairment in multiple sclerosis (MS) patients has been documented, nothing is known about the brain changes sustaining that improvement. To explore this issue, 20 relapsing-remitting MS patients showing AM impairment were randomly assigned in two groups, experimental ( $n=10)$, who underwent the MVI programme, and control $(n=10)$, who followed a sham verbal programme. Besides the stringent AM assessment, the patients underwent structural and functional MRI sessions, consisting in retrieving personal memories, within a pre-/postfacilitation study design. Only the experimental group showed a significant AM improvement in post-facilitation, accompanied by changes in brain activation (medial and lateral frontal regions), functional connectivity (posterior brain regions), and grey matter volume (parahippocampal gyrus). Minor activations and functional connectivity changes were observed in the control group. The MVI programme improved AM in MS patients leading to functional and structural changes reflecting (i) an increase reliance on brain regions sustaining selfreferential process; (ii) a decrease of those reflecting an effortful research process; (iii) better use of neural resources in brain regions sustaining MVI. Functional changes reported in the control group likely reflected ineffective attempts to use the sham strategy in AM.
\end{abstract}

Keywords: autobiographical memory, cognitive rehabilitation, multiple sclerosis, functional neuroimaging, VBM 


\section{Introduction}

The occurrence of cognitive impairment in multiple sclerosis (MS) patients is well established and involves mostly information processing speed, attention, executive functions and anterograde memory (Chiaravalloti \& DeLuca, 2008). Regarding the latter, a more recent line of research has highlighted that retrograde memory, and especially autobiographical memory (AM), is frequently impaired in MS patients (Ernst, Blanc, De Seze, \& Manning, 2015; Ernst, Blanc, De Seze, et al., 2014; Ernst et al., 2013; Müller et al., 2013). AM corresponds to the ability mentally to re-experience personal detailed events within a specific spatio-temporal context (Tulving, 2002) and it has a pivotal role in daily life functioning, especially for the construction and maintenance of personal identity across time, relationships or goal-directed behaviours (Rasmussen \& Habermas, 2011). A critical finding in MS patients is that AM impairment has been reported even in the early stages of the disease and in the context of preserved general cognitive functioning, including anterograde memory (Ernst, Blanc, De Seze, et al., 2014; Ernst, Blanc, Voltzenlogel, et al., 2013). According to these studies, AM could be particularly sensitive to MS pathology but is very rarely explored in clinical routine. As such, the deleterious impact of this impairment in everyday life has probably been underestimated to date, while when exploring AM, MS patients expressed difficulties in daily life related to AM impairment (see Ernst et al., 2014 for excerpts of comments). Based on this, endeavouring to maintain/rehabilitate this ability in MS patients appears clinically relevant.

In this context, one of us (LM) developed a tailor-made mental visual imagery (MVI)based facilitation programme, making use of the cueing role of MVI in AM in relapsingremitting MS (RR-MS) patients. Ernst et al. (2013, 2015) obtained the first results using this programme and reported positive outcomes on AM functioning that was accompanied by an effective transfer in daily life functioning, counteracting the deleterious impact of AM 
impairment previously reported by the patients, and with a long-term robustness of treatment effect.

From a socio-economic standpoint, since cognitive rehabilitation involves certain financial costs, both clinical and cost effectiveness of neuropsychological interventions have been hotly debated across countries, notwithstanding which some scepticism is present (Wilson, 2009). In this context, cognitive interventions are increasingly expected to provide reliable evidence. Besides making it possible to understand underlying brain compensatory mechanisms, neuroimaging techniques could represent useful complementary tools to measure the effectiveness of neuropsychological interventions and, ultimately, as a support for individual adaptation of interventions (Strangman et al., 2005).

Several studies along this line have been conducted in MS patients, showing cerebral functional changes after cognitive interventions aiming to improve attention (Penner, Kappos, Rausch, Opwis, \& Radü, 2006), anterograde memory (Chiaravalloti, Wylie, Leavitt, \& DeLuca, 2012; Leavitt, Wylie, Girgis, Deluca, \& Chiaravalloti, 2014), and in the context of nonspecific interventions (Filippi et al., 2012; Parisi et al., 2014). In a preliminary study, Ernst et al. (2012) also reported increased activation in the posterior brain regions associated with a significant improvement of AM performance following the MVI programme. Overall, converging results were obtained from these studies, showing increased brain activation or higher functional connectivity in specific brain regions after rehabilitation. However, to our knowledge, none of these studies investigated simultaneously the occurrence of brain activation, functional connectivity and structural changes in MS patients after AM rehabilitation.

On these bases, the aim of the present study was to explore both the functional and structural brain changes associated with AM improvement in RR-MS patients. Using the MVI programme (Ernst et al., 2013, 2015), we expected a significant AM improvement in RR-MS patients and that this clinical benefit would be accompanied by significant functional and 
structural changes within the AM brain network (prefrontal cortex, medial and lateral temporal cortices, parieto-occipital regions and the temporo-parietal junction; see Svoboda, McKinnon, \& Levine, 2006 for a review). Specifically, we hypothesised that (1) main functional and structural changes after facilitation would be observed in the posterior brain regions, given their role in MVI processes (Greenberg \& Rubin, 2003) and (2) that these changes would not be observed after a control programme, where no AM improvement is expected.

\section{Methods}

\section{Participants}

Twenty RR-MS patients, with definite MS according to the revised McDonald's criteria (Polman et al., 2011) and who participated in previous studies (Ernst et al., 2014, 2015, 2015), were selected with the following inclusion criteria: an Expanded Disability Status Scale (EDSS; Kurtzke, 1983) score $\leq 4$, no recent exacerbation of MS symptoms, right-handedness, absence of major signs of depression according to the Montgomery and Asberg Depression Rating Scale (score $\leq 15$; Montgomery \& Asberg, 1979), impaired AM performance (number of internal details $\leq 22$; Ernst et al., 2015) in the context of only mild to moderate cognitive impairment in attention and/or executive functions (see Behavioural assessment). These additional inclusion criteria were set to control the presence of confounding factors on AM performance and to guarantee completion of the facilitation programme.

Patients were randomly assigned to two groups using a computerised random number generator and were blind to their allocation group (experimental or control). Importantly, our patients had never previously participated in similar studies. The presentation of the study informed patients of the constitution of different groups of participants, with two possible interventions, the efficacy of which was going to be tested during the study. Patients from the experimental and the control groups were matched for age (mean \pm SD: $38.40 \pm 10.94$ years 
and $37.40 \pm 8.84$ years, respectively; $\mathrm{t}=0.22 ; \mathrm{p}=.82$ ), education (mean: $13.40 \pm 2.22$ years and $12.20 \pm 1.55$ years, respectively; $\mathrm{t}=1.40 ; \mathrm{p}=.17)$, female/male ratio $(6 / 4$ and $9 / 1$, respectively; $\chi 2=2.40 ; \mathrm{p}=.12$ ), EDSS (mean: $2.45 \pm 1.73$ and $2.45 \pm 1.40$, respectively; $\mathrm{t}=$ $0.00 ; \mathrm{p}=1.00)$ and duration of disease (mean: $11.10 \pm 11.03$ years and $10.60 \pm 5.66$ years, respectively; $\mathrm{t}=0.12 ; \mathrm{p}=.90)$. All the patients had been treated with natalizumab (Tysabri®) for at least two years or more, were on stable medication and were at least one-month post their most recent exacerbation.

The study was approved by the Committee for Protection of Persons (CPP/CNRS $\mathrm{N}^{\circ}$ 07023) and complied with the Declaration of Helsinki. All participants gave their written informed consent.

\section{Behavioural assessment}

Prior to inclusion, all the patients underwent a comprehensive neuropsychological baseline assessment (see Table 1) in order to obtain descriptive data on their general cognitive status. In comparison with the normative data provided for each test, impairment in planning and cognitive estimation abilities were shown in our MS patients. Equivalent performance for all the neuropsychological baseline tests were observed for the two groups of patients, with the exception of the delayed recall of the Rey-Osterrieth Complex Figure (ROCF), for which a lower performance was obtained by the control group. Nevertheless, as their mean score remained in the normal range provided by normative data of the test (Fastenau, Denburg, \& Hufford, 1999), this difference was not taken into account. Additionally, no significant correlation was found between the ROCF delayed recall score and AM measures (i.e., the number of internal and external details, see below), either in the experimental group (internal details: $r=-.27, p=$ n.s.; external details: $r=-.31, p=$ n.s.), nor in the control group (internal details: $r=.10, p=$ n.s.; external details: $r=-.17, p=$ n.s.). Note that all these correlations were 
also non-significant when using AM scores in post-facilitation (experimental group: internal details: $r=.16, p=$ n.s.; external details: $r=-.12, p=$ n.s., and control group: internal details: $r=-.04, p=$ n.s.; external details: $r=-.06, p=$ n.s.).

Table 1. Neuropsychological baseline examination scores: Mean (and SD) for the MS patient groups

\begin{tabular}{|c|c|c|c|}
\hline & MS & oups & Ct ti. to \\
\hline & $\begin{array}{c}\text { Experimental } \\
\text { group }\end{array}$ & Control group & Statstical altanysis \\
\hline Verbal reasoning & & & \\
\hline Verbal IQ - short form & $98.70(16.98)$ & $97.00(11.21)$ & $t=0.26 ; p=0.79$ \\
\hline Nonverbal reasoning & & & \\
\hline PM12 & $9.70(1.15)$ & $8.80(1.93)$ & $t=1.26 ; p=0.22$ \\
\hline Anterograde memory (verbal) & & & \\
\hline RAVLT & & & \\
\hline - Total mean number of words & $11.96(1.17)$ & $12.30(1.17)$ & $t=-0.64 ; p=0.52$ \\
\hline - Delayed recall & $13.90(1.10)$ & $13.20(2.30)$ & $t=0.86 ; p=0.39$ \\
\hline$\underline{\text { Anterograde memory (non-verbal) }}$ & & & \\
\hline ROCF & & & \\
\hline - Copy & $35.20(1.13)$ & $35.50(0.85)$ & $t=-0.66 ; p=0.51$ \\
\hline - Immediate recall & $27.50(7.27)$ & $22.05(4.53)$ & $t=2.01 ; p=0.06$ \\
\hline - Delayed recall & $27.45(6.37)$ & $21.80(4.69)$ & $t=2.25 ; p=0.03^{*}$ \\
\hline Language & & & \\
\hline Deno 100 & $97.60(3.02)$ & $95.90(4.79)$ & $t=0.94 ; p=0.35$ \\
\hline Attentional abilities & & & \\
\hline Stroop & & & \\
\hline - Colours (score T) & $44.90(8.76)$ & $47.90(10.39)$ & $t=-0.69 ; p=0.49$ \\
\hline - Words (score T) & $45.20(5.80)$ & $47.40(8.85)$ & $t=-0.65 ; p=0.51$ \\
\hline - Colours-Word (score T) & $47.90(11.58)$ & $48.60(7.47)$ & $t=-0.16 ; p=0.87$ \\
\hline - Interference score (score $\mathrm{T}$ ) & $50.10(8.87)$ & $50.10(7.05)$ & $t=-0.00 ; p=1.00$ \\
\hline Months back (sec; National Hospital) & $13.20(6.92)$ & $10.40(2.80)$ & $t=1.18 ; p=0.25$ \\
\hline Executive functions & & & \\
\hline Tower of London & & & \\
\hline - Score & $8.90(1.85) * *$ & $8.30(2.11) * *$ & $t=0.67 ; p=0.50$ \\
\hline - Time indices & $20.60(4.06)$ & $17.60(3.63)$ & $t=1.74 ; p=0.09$ \\
\hline Brixton & $15.30(5.37)$ & $12.40(4.25)$ & $t=1.33 ; p=0.19$ \\
\hline Cognitive Estimation & $4.70(3.71) * *$ & $4.50(1.96) * *$ & $t=0.15 ; p=0.88$ \\
\hline Verbal Fluency (National Hospital) & & & \\
\hline - Categorical & $20.70(4.90)$ & $20.00(4.92)$ & $t=0.31 ; p=0.75$ \\
\hline - Phonological & $12.30(3.16)$ & $12.00(3.30)$ & $t=0.20 ; p=0.83$ \\
\hline Information Processing Speed & & & \\
\hline AMIBP subtest & & & \\
\hline - Cognitive & $50.00(10.18)$ & $52.20(7.00)$ & $t=-0.56 ; p=0.58$ \\
\hline - Motor & $42.40(8.42)$ & $53.50(10.95)$ & $t=-1.25 ; p=0.22$ \\
\hline - Error percentage & $1.31(2.77)$ & $3.57(3.73)$ & $t=-1.53 ; p=0.14$ \\
\hline - Corrected score & $55.66(11.87)$ & $57.09(7.84)$ & $t=-0.31 ; p=0.75$ \\
\hline Visuo-perceptual and -spatial abilities & & & \\
\hline
\end{tabular}




\begin{tabular}{|l|c|c|c|} 
VOSP & & \\
- Silhouettes & $22.80(4.10)$ & $22.80(2.66)$ & $t=-0.00 ; p=1.00$ \\
- Cubes Analyses & $9.80(0.42)$ & $9.90(0.32)$ & $t=-0.60 ; p=0.55$ \\
Depression & $6.00(5.63)$ & $6.00(3.89)$ & $t=-0.00 ; p=1.00$ \\
MADRS & $47.49(18.09)$ & $40.24(10.16)$ & $t=1.10 ; p=0.28$ \\
\hline Fatigue & & \\
EMIF-SEP (total) & & \\
\hline
\end{tabular}

Verbal IQ - short form (Axelrod, Ryan, \& Ward, 2011; Wechsler, 1997); PM12: Progressive Matrices 12 (Raven, 1958); RAVLT: ReyAuditory Verbal Learning Test (Rey, 1964); ROCF: Rey-Osterrieth Complex Figure (Rey, 1941); Déno 100 (Kremin, 2002); Stroop Test (Stroop, 1935); Months Back (National Hospital, London); Tower of London (Shallice, 1982); Brixton (Burgess \& Shallice, 1997); Cognitive Estimation Task (Shallice \& Evans, 1972); Verbal Fluency (National Hospital, London); AMIPB: Information Processing Speed Test from the Adult Memory Information Processing Battery (Coughlan \& Hollows, 1985); VOSP: Visual Object and Space Perception (Warrington \& James, 1991); MADRS: Montgomery and Asberg Depression Rating Scale (Montgomery \& Asberg, 1979); EMIF-SEP: Echelle de Mesure de l'Impact de la Fatigue (Debouverie, Pittion-Vouyovitch, Louis, \& Guillemin, 2007)

* Statistical difference between the two groups

** Scores under the normal range (according to the normative data of each test)

In a second session, an AM assessment was carried out by means of the adapted Autobiographical Interview (AI; Addis, Wong, \& Schacter, 2008; Levine, Svoboda, Hay, Winocur, \& Moscovitch, 2002). The adapted AI consists in the evocation of as much detail as possible about temporally and spatially specific personal memories elicited by cue-words. A list of 30 cue-words typically used for AM assessment (e.g., car, cat, house) was established based on previous studies (Crovitz \& Schiffman, 1974; Rubin, Schrauf, \& Greenberg, 2003; Voltzenlogel et al., 2006). Twelve to 15 memories were collected, depending on the patient's age ( $0-11$ years; $12-20$ years; 21 to current age minus 1 or $21-35$ years and 36 to current age minus 1; last year). Patients were informed that the cue-words were intended to be used flexibly and no time limit was set to retrieve a memory.

All the patients underwent the adapted AI twice, once before and once after the intervention. Importantly, cue-words were randomly selected from our list at the first AI session, and the remaining cue-words were used for the second AI assessment- so the cue-words were always different in the pre- and post-facilitation assessments. If, in spite of this, patients evoked memories already provided during the first session, they were asked to find another memory. 
Scoring followed the standardised AI procedure (Levine et al., 2002), distinguishing internal (i.e., episodic detail related to the central event) and external details (i.e., non-episodic information such as semantic details, metacognitive statements, repetitions or episodic details unrelated to the central event). While the main scorer (AE) was not blind to the patient's allocation group, a blind rater verified the scoring accuracy for $20 \%$ of memories randomly chosen. Moreover, as mentioned in a previous study (Ernst et al., 2015), AI reports were anonymised and memories were not supplied for scoring in the chronological order of assessment (i.e., post-facilitation AI from a patient was not systematically given for the second scoring after the pre-facilitation AI) and were mixed with AIs belonging to healthy subjects who participated in the study of Ernst et al. (2014). The reliability between the two scorers was assessed with intraclass correlations and indicated a high agreement for both composites (internal details: .95; external details: .94).

The AM assessment ended with a semi-structured interview (fully described in Ernst et al., 2014), which aimed to characterise the potential impact of AM impairment and the perceived benefits of the intervention during the test session and in everyday life. This semistructured interview took place in pre- and post-facilitation, immediately after the AI session, and included four dimensions: accessibility, amount of detail, vivid-ness, and emotional intensity of memories.

\section{Facilitation programme}

Both MVI and control programmes encompassed six two-hour sessions (individual sessions, one or twice per week). Following a goal-directed approach (Wilson \& Gracey, 2009), the first step was to explain carefully the aim of the programme, its content and how it was supposed to help the memory impairment. This introduction was important to help promote its further use in daily life. Along these lines, the neuropsychologist was very attentive to treatment 
receipt (i.e., the extent to which the patient understands the strategies or techniques taught, and demonstrates the capacity to use them; Hart, 2009). During all the sessions, the neuropsychologist provided continuous guidance (as much as necessary), probing the patient from general aspects to more detailed ones, adopting a "funnel-approach" and learning to work in a sequential manner.

The MVI programme was based on the ability mentally to construct scenes and to pay close attention to details in the mind's eye. The MVI programme comprised four steps, with mental visualisation exercises of increasing difficulty: (1) The screening test was based on three subtests from the Imagery and Perception Battery (Bourlon et al., 2009). The aim of this step was to probe basic visual imaging abilities, which enabled us to exclude patients who presented major visual imaging impairment undetected during the neuropsychological baseline and therefore incompatible with the implementation of the facilitation programme (note, however, that we never had to exclude a patient at this stage). (2) The external visualisation included 10 verbal items to imagine and describe in as much detail as possible (e.g., shape, colour, size, etc.), with the complementary visualisation of an action made with the item (e.g., visualise a ladybird and visualise it flying away). (3) The construction phase consisted in figuring out complex scenes, bringing into play several characters and various scenarios. Five verbal items were proposed for each part of the exercise: a first training step (e.g., imagine a hotel you stayed at on holiday) and a subsequent mental scene construction, sharing thematic similarities (e.g., imagine the house of your dreams), allowing the patient to rely on the training section to construct the next scene. (4) The self-visualisation phase followed the same procedure but here patients were asked to visualise them-selves within a given scenario, to imagine it as though they were actually living the scene, with the description of all kinds of details, sensations or feelings that came to mind. A first training scene was proposed (e.g., imagine you are taking 
part in a magic show), followed by a second scene with a similar theme (e.g., imagine you are entering the big cats' cage for a show).

The control programme followed the same procedure but focused on the narrative structure, which plays a minor role in AM relative to MVI (Greenberg \& Rubin, 2003). The common theme was to construct discussions about texts, going from discussion about the form, to the theme of the text, with a final focus on the patient's personal opinion, with a particular emphasis on the organisation of information. Three steps were pro-posed: (1) The external discussion relied on the identification of influent variables on text understanding related to its form (e.g., clarity, vocabulary used) and comprised 20 texts. This step was very brief and corresponded to the MVI external visualisation programme. (2) The discussion construction comprised five items, with a training and a construction step for each item, with two texts thematically related to enable reliance on the first to construct the second (e.g., a first text dealing with a trip to South Africa was followed by a text about a trip to Ireland). (3) The selfinvolved discussion was similar to the previous step, with the addition of questions about the participant's own opinion (e.g., a first text about taxing sodas to reduce their consumption was followed by a second text concerning the usefulness of anti-smoking campaigns).

The same neuropsychologist administered the two programmes to ensure that the general approach and dynamics of the sessions were similar for each patient, whatever their allocation group. Thus, the neuropsychologist was not blind to the patient's group membership. However, we designed our study in agreement with the recommendations of the Neuropsychological Rehabilitation Consensus Conference (Làdavass, Pao-lucci, \& Umiltà, 2011), which acknowledged that the criterion of the blindness of the neuropsychologist to allocation is sometimes difficult to set, such as in the context of a goal-directed approach as used in our study. In addition, as mentioned earlier, to control the potential influence of the 
investigator's awareness of the patient's group allocation, the second AI scorer was blind to group membership.

\section{Neuroimaging session}

fMRI tasks

Prior to scanning, the procedure was explained to the patients and they completed a computerised practice trial for each task in order to be familiar with the experimental design and timing of presentation of the stimuli. Taking into account the time constraints imposed by fMRI, particular attention was paid to this practice trial to optimise completion of the task by the patients. Thus, the practice was repeated as much as necessary before entering the scan, and complementary explanations were provided if necessary. This procedure was strictly followed for both fMRI sessions, even if the session functioning was familiar to patients in postfacilitation. Importantly, patients were asked to remember memories different from those provided during the first fMRI session and this was further verified based on the post-scan questionnaire (see below).

Two fMRI tasks were completed during scanning, each with two versions for the preand post-facilitation sessions (presented in a counterbalanced order). The experimental task (i.e., AM condition) consisted in the evocation of unique personal past events, contextually specific, occurring over minutes or hours, but no longer than one day. The similarity with the event's characteristics of the adapted AI was reminded to promote good understanding of the task, and examples were provided. Thirty-two pairs of words were proposed to elicit memories, covering the same life periods as in the AI. The rationale to present cues in pairs, instead of as a single cue-word, was clinically based. Given that the fMRI task imposes time-constraints, and taking into account that the included MS patients initially showed AM impairment, the use of pairs of words was deemed better adjusted to obtain a sufficient number of events per condition. Within 
each pair, the two words were thematically related and their relevance to probe memories was verified in a pilot study with 12 healthy participants (unpublished data; see Appendix for examples of cues). Based on Addis, Wong, and Schacter (2007), we distinguished: (1) the construction phase corresponding to the search and initial building up of the memory, and (2) the elaboration phase corresponding to the retrieval of details associated with the memory.

The control task was a categorical task that included 32 pairs of words, which patients had to include in a sentence for the construction phase. Once the sentence was constructed, during the elaboration phase, patients had to keep the same sentence structure, replacing the two given cue-words with words of the same semantic category.

For both tasks, each trial had a fixed duration of $20 \mathrm{sec}$ modulated by the subject's response: patients pressed button 1 on a 4-button response box to mark the end of the construction phase. Then, a central fixation cross indicated the elaboration phase, which lasted during the remaining time. Importantly, patients were instructed to press the button only if an event came to their mind. In the absence of answer from patients, the next trial was automatically presented after the fixed trial duration of $20 \mathrm{sec}$.

The experimental design was organised in eight functional runs of eight stimuli (four functional runs per condition), alternating between AM and control conditions. In both tasks, each trial was followed by short periods of fixation that were of random duration (mean duration $=1.5 \mathrm{~s}$, range $=1-2 \mathrm{~s})$. At the beginning of each sequence, the name of the condition was displayed on the screen for $6 \mathrm{sec}$. The presentation order of stimuli within each condition was randomised. The tasks and the experimental design are illustrated in Figure 1.

The programming and response collection was done with E-Prime 2 software (Psychology Software Tools, Inc.). Words were displayed on a screen in white text with a black background and viewed using a mirror incorporated in the head-coil. 


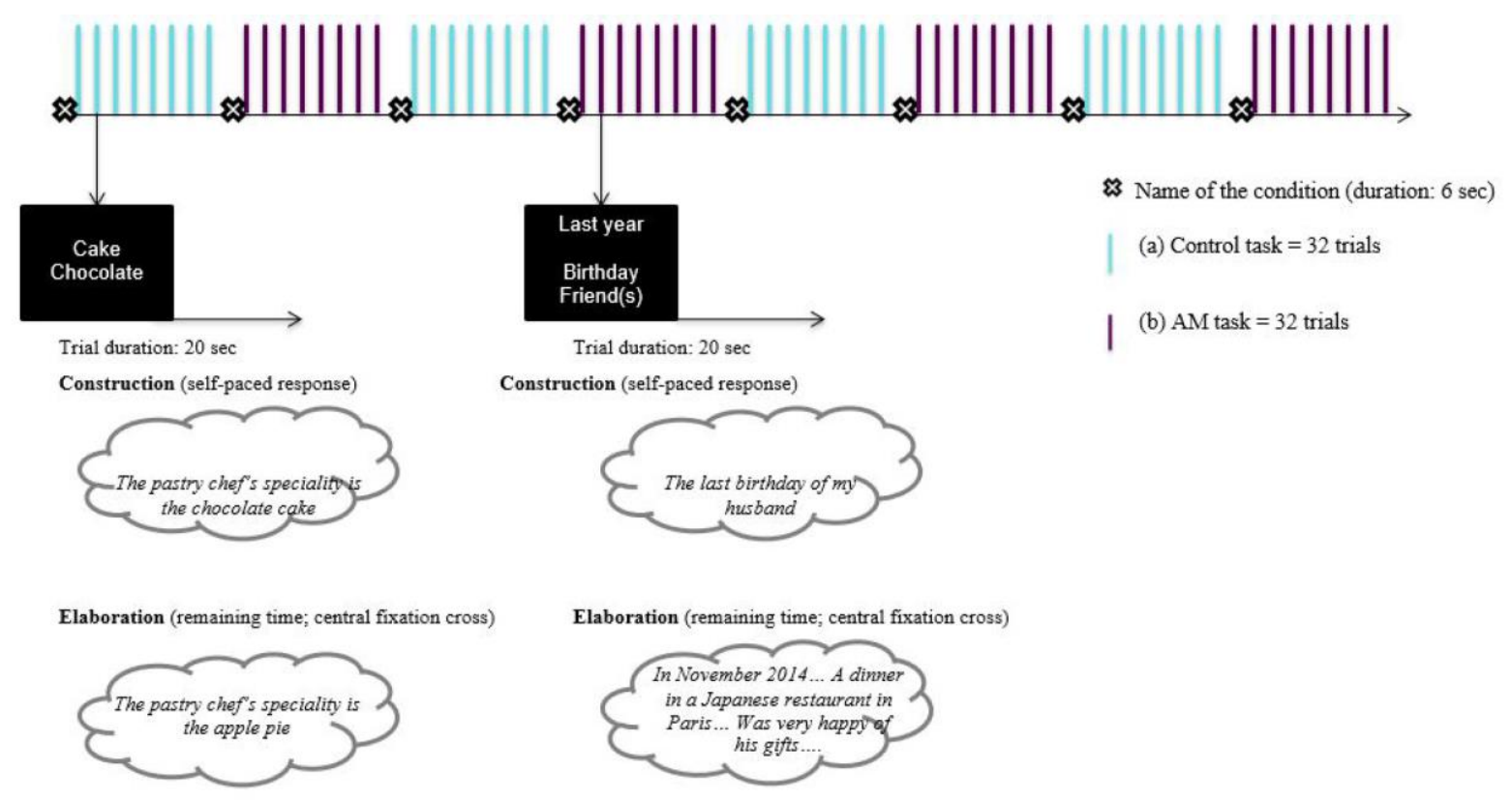

Figure 1. Schematic illustration of the fMRI tasks and experimental design.

Immediately following scanning, a post-scan questionnaire was completed in order to verify response accuracy and exclude invalid trials. For each memory, patients indicated the type of event (unique, repetitive, extensive, semantic or absent). The different types of memories were defined as follow: (1) unique: specific or particular occurrence of events, within a specific time and space frame, no longer than one day; (2) repetitive: composed of event memories, which are usual and repeated, and thus lack episodicity; (3) extended: includes events whose duration is longer than one day (e.g., my week's holiday in Rome), without the mention of a specific incident; (4) semantic: encompasses general, semantic associations with the cue-words not self-relevant (i.e., there is often snow at Christmas); (5) absent: corresponds to the absence of response in the scanner (i.e., no button press to end the construction phase). Patients were also asked to provide the spatio-temporal context of memories and rate on a visual-analogous scale of $10 \mathrm{~cm}$ the amount of detail $(0 \mathrm{~cm}$, corresponding to a low amount of 
detail; $10 \mathrm{~cm}$, corresponding to a high amount of detail). For the spatio-temporal context, participants were asked to write down the most detailed account they were able to about the location of the event and when it occurred. Regarding the type of event, while patients initially determined the specificity of memories, a further control of this aspect was made by the experimenter (AE), based on the spatial-temporal context of events. More precisely, immediately after completion of the post-scan questionnaire, in the absence of a specific spatiotemporal context (necessary to consider an event as unique) or in the case of doubt regarding the classification, patients were asked to provide additional details about the event to determine its precise nature.

The general study procedure is illustrated in Figure 2. Please note that after the second MRI session, all the patients from the control group were offered the MVI programme.

fMRI acquisition parameters

MRI examinations were performed on a 3 T MRI scanner (MAGNETOM Verio, Siemens Healthcare, Erlangen, Germany). Structural images were obtained by means of a 3D T1weighted SPACE (Sampling Perfection with Application optimised Contrasts using different flip angle Evolution) sequence $\left(\mathrm{TR}=4000 \mathrm{~ms}, \mathrm{TI}=380 \mathrm{~ms}, \mathrm{TE}=383 \mathrm{~ms}\right.$, flip angle $=120^{\circ}$, $\mathrm{FOV}=256 \mathrm{~mm}$, matrix $=512 \times 512,176$ sagittal slices of $1 \mathrm{~mm}) .3 \mathrm{D}$ T2 Fast Spin Echo images were also acquired with the following parameters: $\mathrm{TR}=3200 \mathrm{~ms}$, TE $=409 \mathrm{~ms}$, flip angle $=$ $120^{\circ}, \mathrm{FOV}=256 \mathrm{~mm}$, matrix $=512 \times 512,176$ sagittal slices of $1 \mathrm{~mm}$.

Functional images were acquired with a $\mathrm{T} 2 *$-weighted echo planar imaging sequence $(\mathrm{TR}=2500 \mathrm{~ms}, \mathrm{TE}=30 \mathrm{~ms}$, Voxel size $=3.5 \times 3.5 \times 3.5 \mathrm{~mm} 3$, Matrix $=64 \times 64 \times 45$ voxels, $\mathrm{FOV}=225 \times 225 \times 157.5 \mathrm{~mm}, \mathrm{FA}=90)$. Slices were orientated parallel to the anterior commissure and posterior commissure plane to cover the whole brain. 


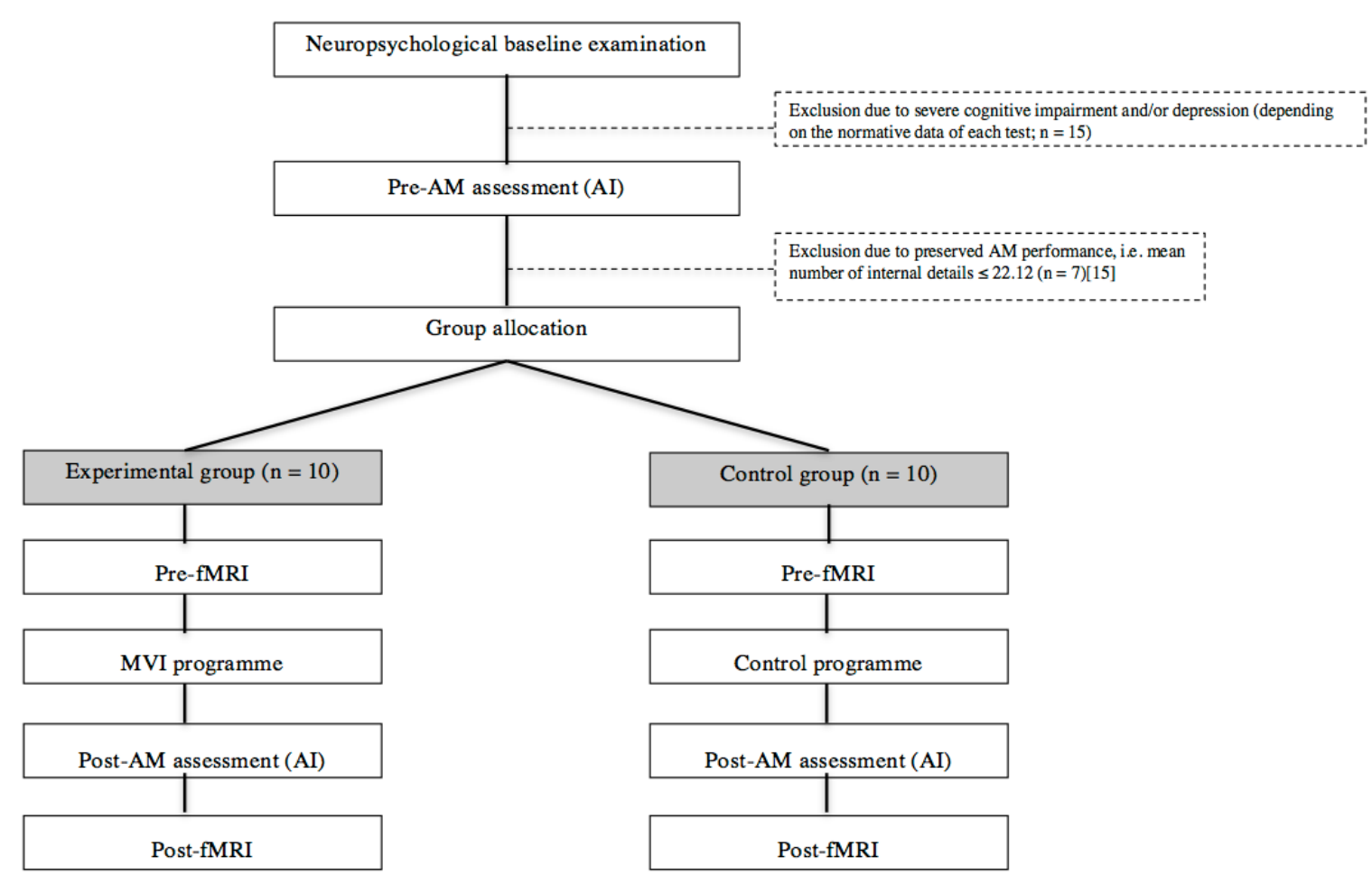

Figure 2. Study design diagram summarising the group allocation and progression through study

phases.

\section{Statistical analyses}

Behavioural data

Repeated-measures ANOVAs were run for all the post-scan variables and for the AI performance with the between-factor of Group and the within-factor of Time (pre- and postfacilitation) and of Detail (internal and external; only for the AI).

Neuroimaging analyses

All the analyses were conducted using SPM8 (Welcome Department of Cognitive Neurology, London, UK). Images were pre-processed as follows: time series were realigned to the first volume to correct for motion artefacts, spatially normalised to a standard EPI template based on the Montreal Neurological Institute reference brain in Talairach space (Talairach \& 
Tournoux, 1988) and spatially smoothed using an $8 \mathrm{~mm}$ full-width at half-maximum isotropic Gaussian kernel. For the AM and control tasks, evoked haemodynamic responses time locked to the onset of the cue presentation (construction phase) were modelled with a canonical haemodynamic response function. Haemodynamic activity related to the elaboration phase was modelled with a boxcar function of 10 sec-duration that started immediately after the end of the construction phase indicated by a button press. The $10 \mathrm{sec}$-duration interval for the elaboration phase was fixed to allow a sufficient time interval for the search for details, and trials with a construction phase longer than $10 \mathrm{sec}$ were excluded.

Regarding the fMRI analysis, in the context of the general linear model, statistical parametric maps were generated for each subject, in both sessions, for the further contrasts: $\mathrm{AM}$ construction $>$ control task construction and $\mathrm{AM}$ elaboration $>$ control task elaboration. Statistical parametric maps were entered into a second level of analysis for between-group comparisons in pre-facilitation (two-sample t-test). Within-group comparisons were then conducted between pre- and post-facilitation sessions (paired t-test) for each group. The significance threshold was set at $\mathrm{p}<.05$ (corrected for multiple comparisons). Due to the exploratory nature of this study, in the case of no significant results, analyses were also conducted at $\mathrm{p}<.001$ (uncorrected) with an extent threshold of 20 contiguously activated voxels, to give a more informative overview of the results. Note however that the latest threshold has been commonly used in AM literature (Addis et al., 2007; Botzung, Denkova, Ciuciu, Scheiber, \& Manning, 2008).

Regarding the functional connectivity (FC) analysis, a group independent component analysis (ICA) was performed for each condition, with an implementation of the infomax algorithm (Bell \& Sejnowski, 1995), as provided by the GIFT v3.0 toolbox (http://mialab.mrn.org/software/, 2004). Construction and elaboration phases were analysed as a whole and only valid trials were entered into these analyses. Dimensionality was previously 
reduced by two principal component analyses, according to the automatic estimator available in GIFT, 70 and $30.7( \pm 1.5)$ principal components were retained at the individual level and group level, respectively. The group ICA was repeated 10 times using ICASSO (Himberg, Hyvärinen, \& Esposito, 2004) to ensure reliability of the components. Based on the relationships between mental time travel, MVI and the default mode network (DMN), the posterior DMN (PDMN) was selected as the network of a priori interest (Andrews-Hanna, Reidler, Sepulcre, Poulin, \& Buckner, 2010). The PDMN was manually selected among all the independent components and recorded as z-score 3D maps. Subject-specific PDMN were backreconstructed (Calhoun, Adali, Pearlson, \& Pekar, 2001) and then spatially compared by contrasting pre- and post-facilitation sessions (paired t-tests for each group). Statistical analyses were masked by a binarised version of the network, i.e., all the brain areas involved in at least one of the two sessions. Following Leavitt et al. (2014), the statistical threshold was set at p $<.05$ corrected for multiple comparisons with a minimum extent threshold of five contiguously activated voxels. Again, in the case of no significant results, exploratory analyses were run at $\mathrm{p}<.001$ (uncorrected).

Structural neuroimaging analysis was performed using the Voxel-Based Morphometry framework provided in SPM8. Correlations between local grey matter (GM) volume evolution and AM performance progression were explored within each group $(\mathrm{p}<.05$, corrected for multiple comparisons). Due to an MRI acquisition problem, one patient from the experimental group was excluded from the voxel-based morphometry (VBM) analysis. To provide an informative overview of the results, a more lenient statistical threshold of $\mathrm{p}<.001$ (uncorrected) was applied in the case of no significant result with a corrected threshold.

\section{Results}

Behavioural results 
AI performance

Focusing on the results dealing with the changes in AM performance in the two groups across time, a significant Group $\times$ Time $\times$ Detail was found, $F(1,18)=7.25, p=.01, h 2 p=$ 0.28. Tukey HSD post-hoc test revealed that while no significant difference was observed between the two groups before facilitation (internal details: $p=.99$; external details: $p=.99$ ), after facilitation, a greater number of internal details was shown in the experimental relative to the control group $(\mathrm{p}=.03$; however not significant when applying a corrected $\mathrm{p}$-value for multiple comparisons set at $p=.006$ ), but equivalent performance was observed between the two groups for external details $(\mathrm{p}=.99)$.

Within-group comparisons showed, in post-facilitation, a significant increase of the number of internal details in the experimental group $(p<.001)$ but not in the control group $(p=.29)$. Stable performance was observed for the external details across sessions for both the experimental ( $p$ $=.55)$ and the control $(\mathrm{p}=.59)$ group (Figure 3$)$. 


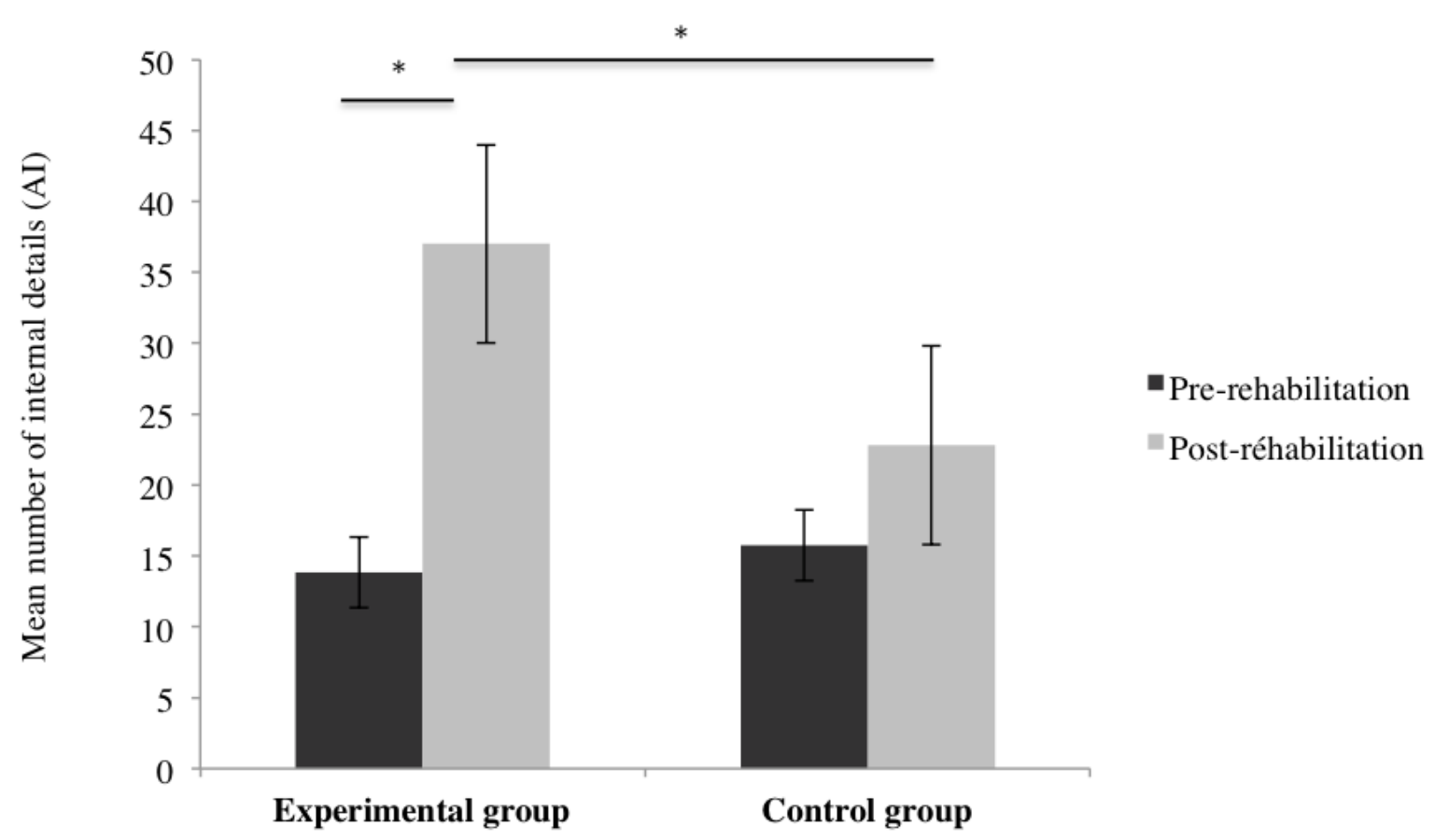

Figure 3. Mean number of internal details provided by the patient groups in pre- and post-facilitation (*significant difference). Dotted line: initial normative score showing AM impairment (Ernst et al., 2015).

\section{Semi-structured interview}

Patients' comments collected by means of the semi-structured interview supported the benefits of the MVI programme on the different AM dimensions explored (accessibility, amount of details, emotional intensity and vividness), with an effective transfer to every-day life functioning. Examples of patient's comments are:

Patient 1: "Yes, there are more details than the last time. Actually, it's as if I am wearing reading glasses now in comparison with the last time. It used to be more or less blurred, but now, it seems more fluent to me, it comes very quickly."

Patient 2: "I think that I found it quicker and it was clearer than the first time we went through these exercises. Even when I remembered a scene, before, I saw it from far away, while now, the feeling is that I've relived some events at the present 
time. It's true that sometimes, you realise that the sessions are gaining their own place. It's not every time but sometimes, you've gone a bit of the path, it's done without really realising it. I would never have thought that I could use little tricks like this. It's something that could help me anyway in my life."

Patient 3: "Yes, I visualise things much more than before. Before, it was superficial and now, I'm really in, I'm seeing myself in my mind. I'm going into details, how things really happened."

\section{Post-scan results}

Results from the post-scan questionnaire are summarized in Table 2.

Table 2. Behavioural results from the neuroimaging sessions for the experimental and control patient groups in pre- and post-facilitation

\begin{tabular}{|c|c|c|c|c|c|c|}
\hline & \multicolumn{2}{|c|}{$\begin{array}{l}\text { Experimental } \\
\text { group }\end{array}$} & \multicolumn{2}{|c|}{ Control group } & \multirow[t]{2}{*}{$\begin{array}{l}\text { Between-group } \\
\text { comparison }\end{array}$} & \multirow[t]{2}{*}{$\begin{array}{c}\text { Pre-post } \\
\text { comparison }\end{array}$} \\
\hline & PRE & POST & PRE & POST & & \\
\hline $\begin{array}{l}\text { Construction } \\
\text { (sec) }\end{array}$ & $\begin{array}{c}4.83 \\
(1.31)\end{array}$ & $\begin{array}{c}5.50 \\
(1.13)\end{array}$ & $\begin{array}{c}5.16 \\
(0.77)\end{array}$ & $\begin{array}{c}4.98 \\
(1.18)\end{array}$ & $\begin{array}{c}F(1,18)=0.04, p \\
=0.83\end{array}$ & $\begin{array}{c}F(1,18)=1.17, p \\
=0.29\end{array}$ \\
\hline \multicolumn{7}{|l|}{$\begin{array}{l}\text { Type of events (mean } \\
\text { number) }\end{array}$} \\
\hline Unique & $\begin{array}{l}17.20 \\
(7.22)\end{array}$ & $\begin{array}{l}23.80 \\
(5.26)\end{array}$ & $\begin{array}{l}17.00 \\
(6.34)\end{array}$ & $\begin{array}{l}22.90 \\
(4.22)\end{array}$ & & \\
\hline Repetitive & $\begin{array}{c}4.20 \\
(1.93)\end{array}$ & $\begin{array}{c}2.70 \\
(4.59)\end{array}$ & $\begin{array}{c}5.50 \\
(5.35)\end{array}$ & $\begin{array}{c}2.40 \\
(2.41)\end{array}$ & & \\
\hline Extended & $\begin{array}{c}1.10 \\
(1.37)\end{array}$ & $\begin{array}{c}0.40 \\
(1.26)\end{array}$ & $\begin{array}{c}0.90 \\
(1.85)\end{array}$ & $\begin{array}{c}0.40 \\
(1.26)\end{array}$ & $\begin{array}{l}F(1,18)=2.84, p \\
=0.10\end{array}$ & $\begin{array}{c}F(1,18)=6.00, p \\
=0.02\end{array}$ \\
\hline Semantic & $\begin{array}{c}1.20 \\
(2.14)\end{array}$ & $\begin{array}{c}0.30 \\
(0.67)\end{array}$ & $\begin{array}{c}1.80 \\
(3.29)\end{array}$ & $\begin{array}{c}1.30 \\
(2.49)\end{array}$ & & \\
\hline Absent & $\begin{array}{c}2.90 \\
(3.95)\end{array}$ & $\begin{array}{c}1.80 \\
(1.98)\end{array}$ & $\begin{array}{c}2.90 \\
(2.88)\end{array}$ & $\begin{array}{c}3.10 \\
(3.34)\end{array}$ & & \\
\hline $\begin{array}{l}\text { Amount of details } \\
\text { (mean) }\end{array}$ & $\begin{array}{c}5.11 \\
(1.73)\end{array}$ & $\begin{array}{l}5.95 \\
(2.08)\end{array}$ & $\begin{array}{c}6.64 \\
(0.76)\end{array}$ & $\begin{array}{c}6.26 \\
(1.72)\end{array}$ & $\begin{array}{c}F(1,18)=1.88, p \\
=0.18\end{array}$ & $\begin{array}{c}F(1,18)=0.56, p \\
=0.46\end{array}$ \\
\hline
\end{tabular}

RT: reaction time; PRE / POST: pre-facilitation / post-facilitation 
Neither a significant main effect of Group nor of Time was observed for the mean construction reaction time and the amount of detail. No significant Group $\times$ Time inter-actions were shown for the mean construction reaction time and the amount of detail.

Regarding the type of events, no main effect of Group was reported but a significant main effect of Time was revealed, showing a greater number of events in post-facilitation. A main effect of event type was obtained, $\mathrm{F}(4,72)=109.51, \mathrm{p}<.001$, showing a greater number of unique events relative to the other types $(p<.001$ in all the cases). No difference was found between the other types (between $p=.06$ and $p=99$ ). A significant Time $\times$ Event type interaction was displayed, $\mathrm{F}(4,72)=13.77, \mathrm{p}<.001$, revealing an increased number of unique events in post-facilitation $(\mathrm{p}<.001)$, while stable results were obtained for the remaining categories (repetitive: $p=.25$; extended: $p=.99$; semantic: $p=.99$; absent: $p=.99$ ). Neither a significant Group $\times$ Time nor a Group $\times$ Event type interaction was shown.

\section{Neuroimaging results}

Prior to intervention, no significant between-group difference was observed within the AM brain network.

\section{Experimental group}

Regarding brain activation changes, no cluster reached statistical significance using a corrected threshold but the following results were observed at $\mathrm{p}<.001$ (uncorrected). In postfacilitation, during AM construction, enhanced neural activity was displayed in the left medial frontal regions and the right thalamus (Table 3). The reverse contrast showed no greater activation in pre- than in post-facilitation. During AM elaboration, no supra-threshold cluster was obtained in post- vs. pre-facilitation. The reverse contrast (pre- vs. post-facilitation) revealed greater activations in the left middle and inferior frontal gyrus, the left fusiform gyrus 
and the left cerebellum (Table 3; Figure 4). As illustrated in Figure 4, the pattern of brain activation changes in pre- and post-facilitation observed in the experimental group was not evident in the control group for these brain regions.

Table 3. Brain activation changes in pre- and post-facilitation observed in the experimental group during AM construction and elaboration ( $p<0.001$ uncorrected; $k=20$ voxels)

\begin{tabular}{|c|c|c|c|}
\hline Brain region & $\begin{array}{c}\text { Coordinates } \\
(x, y, z)\end{array}$ & Z-score & Cluster size \\
\hline \multicolumn{4}{|l|}{ Pre-facilitation $>$ Post-facilitation } \\
\hline \multicolumn{4}{|l|}{ AM construction (vs. control task construction) } \\
\hline \multicolumn{4}{|l|}{ No significant cluster } \\
\hline \multicolumn{4}{|l|}{ AM elaboration (vs. control task elaboration) } \\
\hline L Middle frontal gyrus (BA 11) & $-42,52,-14$ & 4.22 & 40 \\
\hline L Inferior frontal gyrus (BA 47) & $-16,28,-16$ & 4.14 & 73 \\
\hline L Fusiform gyrus (BA 37) & $-38,-48,-8$ & 4.02 & 45 \\
\hline L Cerebellum & $-12,-38,-24$ & 4.58 & 91 \\
\hline \multicolumn{4}{|l|}{ Post-facilitation $>$ Pre-facilitation } \\
\hline \multicolumn{4}{|l|}{ AM construction (vs. control task construction) } \\
\hline L Medial frontal gyrus (BA 10) & $-10,56,16$ & 4.08 & 43 \\
\hline L Medial frontal gyrus (BA 11) & $0,36,-12$ & 3.72 & 23 \\
\hline R Thalamus & $8,-16,8$ & 3.63 & 20 \\
\hline \multicolumn{4}{|l|}{ AM elaboration (vs. control task elaboration) } \\
\hline No significant cluster & & & \\
\hline
\end{tabular}


(A) Post-facilitation > Pre-facilitation
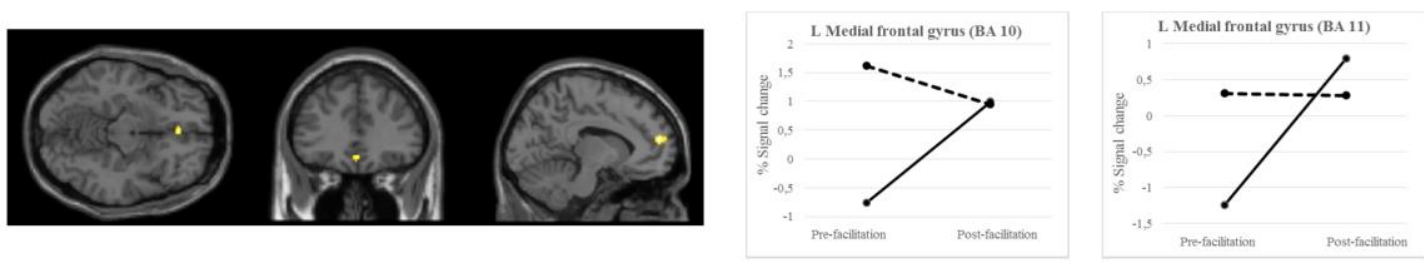

(B) Pre-facilitation > Post-facilitation
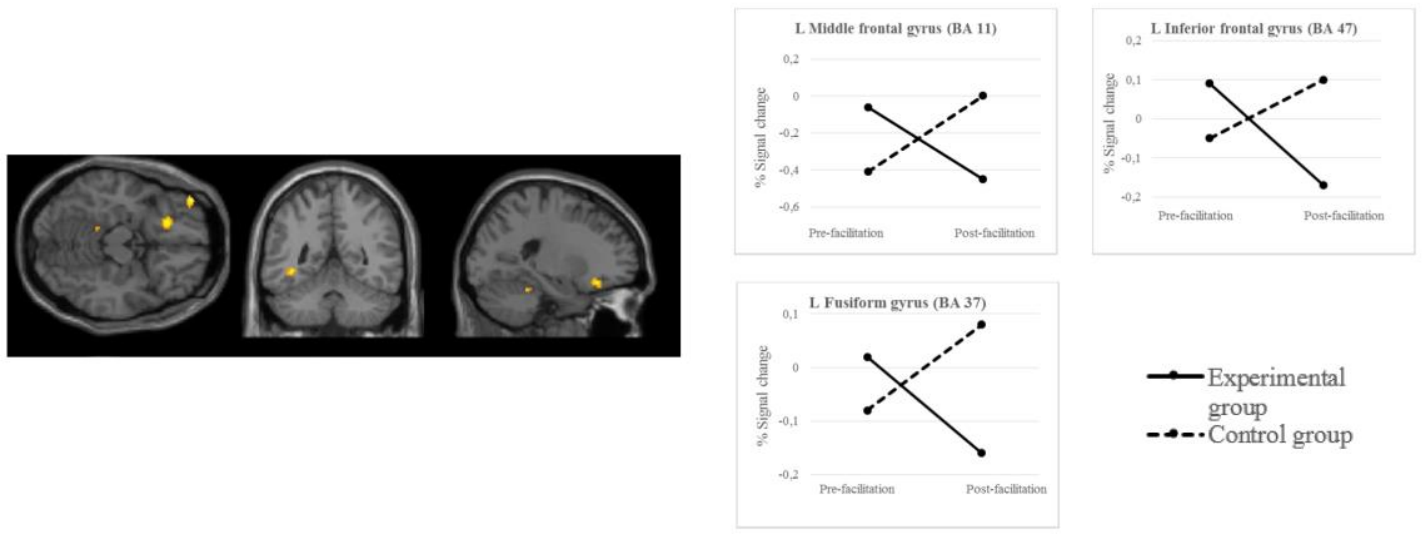

Figure 4. Brain regions showing (a) increased activations in post-facilitation (vs. pre-

facilitation) during AM construction and (b) greater activation in pre-facilitation (vs. post-facilitation) during AM elaboration within the experimental group $(\mathrm{p}<.001$ uncorrected; $\mathrm{k}=20$ voxels). Percent signal change data associated with each of these conditions (pre- and post-facilitation) were extracted from the peak voxels of these clusters (see Table 3 for coordinates) and were plotted for each group. L and $\mathrm{R}$ refer to left and right hemisphere, respectively. $\mathrm{BA}=$ Brodmann area.

Regarding functional connectivity measures (Table 4), significant changes were observed within the PDMN but only in pre- vs. post-facilitation, showing a higher functional connectivity in the bilateral posterior cingulate gyrus and the right precuneus before facilitation ( $p<.05$, corrected for multiple comparisons). 
Table 4. Functional connectivity changes before and after facilitation in the experimental and the control groups (FWE, $p<0.05, \mathrm{k}=5$ voxels)

\begin{tabular}{lccc}
\hline Brain region & Coordinates (x, y, z) & Z-score & Cluster size \\
\hline Experimental group & & & \\
Pre-facilitation > Post-facilitation & & & \\
L Cingulate gyrus (BA 31) & $-1,-46,27$ & 5.72 & 34 \\
R Precuneus (BA 31) & $10,-53,31$ & 4.46 & \\
R Cingulate gyrus (BA 23) & $3,-21,31$ & 4.85 & 5 \\
& & & \\
Post-facilitation > Pre-facilitation & & & \\
No significant cluster & & & \\
Control group & & & \\
Pre-facilitation > Post-facilitation & & & \\
No significant cluster & & & \\
& & & \\
Post-facilitation > Pre-facilitation & $41,49,-8$ & 5.20 & 5 \\
R Middle frontal gyrus (BA 11) & $-36,28,10$ & 4.84 & 6 \\
L Inferior frontal gyrus (BA 13) & $27,32,52$ & 5.23 & 14 \\
R Superior frontal gyrus (BA 8) & & & \\
\hline
\end{tabular}

Turning to VBM analyses, the AI score progression in post-facilitation was significantly and positively associated with increased GM volume in the left parahippocampal gyrus (xyz: $-32,-2,-22$; Z-score: 3.28 ; cluster size: 4), but this result was only evident using an uncorrected p-value. This positive correlation between AI score progression and the GM in the left parahippocampal gyrus in the experimental group is illustrated in Figure 5, which also shows that no such correlation was found in the control group in this brain region.

\section{Control group}

The following brain activation changes were only evident at $\mathrm{p}<.001$ (uncorrected). While no brain activation change was observed during AM construction in post- vs. prefacilitation, increased brain activations were shown during AM elaboration in the left superior frontal gyrus (BA 6; xyz: -8, 38, 60; Z-score: 3.86). The pre- vs. post-facilitation comparisons 
showed increased activity in the left medial frontal gyrus (BA 10; xyz: $-10,60$, 4; Z-score: 3.55) during AM construction, but no significant change during AM elaboration.

Higher functional connectivity was only observed in the bilateral frontal regions $(\mathrm{p}<.05$, corrected for multiple comparisons; Table 4) in post- vs. pre-facilitation. In parallel, no significant GM volume change associated with AI score was observed (even at $\mathrm{p}<.001$, uncorrected).

\section{Discussion}

The present study aimed at probing the efficacy of an MVI facilitation programme on AM impairment, by testing clinical, functional and structural brain changes in RR-MS patients. Prior to facilitation, no group differences were detected either at neuropsychological or neuroimaging levels. The patient groups obtained similar fMRI behavioural performance in terms of mean RT or number of valid trials across time meaning that the different brain changes between groups were not due to different levels of fMRI performance. As expected, the clinical benefit observed in the experimental group was accompanied by functional and structural brain changes in key nodes of the AM brain network. Contrary to our expectations, despite the absence of significant AM improvement, minor functional brain changes were reported in the control group.

In keeping with previous studies (Ernst et al., 2013, 2015) patients from the experimental group showed improved AM performance after facilitation, with an effective transfer of benefits to daily functioning (see also Ernst et al., 2015). The benefit of the MVI programme was specific to internal details, namely details that are episodic in nature, which were the primary focus of this intervention. In addition, since semantic aspects of AM have been found to be preserved in MS patients (Ernst et al., 2013), there was also little margin to observe significant improvement for external/non-episodic details. Conversely, no clinical 
changes were reported in the control group, which presented with similar demographic, clinical and general cognitive functioning characteristics to the experimental group. Nevertheless, while both groups showed pre-served anterograde memory, a slight difference in terms of visual memory performance (ROCF delayed recall) was observed between the two groups, with the control group obtaining a lower score than the experimental group. However, the absence of a significant correlation between this visual memory score and AM scores (also previously observed in Ernst et al., 2013) supports the idea that this slight difference did not impact on the current results. As such, the findings obtained in the control group led us to exclude the main influence of nursing effects on the outcome with the MVI programme in the experimental group.

Regarding the functional underpinnings of AM improvement, increased brain activations in the medial frontal regions were particularly apparent during AM construction. These regions are strongly involved in AM and sustain the self-referential process (Northoff et al., 2006). According to the concept of subjective sense of remembering (Greenberg \& Rubin, 2003), we suggest that the MVI programme, by improving the quality of memories, led to a greater sense of self-involvement during memory recollection. During the elaboration phase, no brain activation changes were noticed in the experimental group after facilitation. However, brain regions showing increased activation before facilitation should be considered here. The latter include the lateral frontal region and the fusiform gyrus, for which increased neural activity - modulated by the amount of detail provided - has been observed in MS patients in the context of AM impairment (Ernst et al., 2015). These findings lead us to interpret the decreased brain activation post-facilitation as reflecting diminished effortful processes.

Contrary to our main hypothesis and the results of Ernst et al.'s (2012) preliminary study, no signs of up-regulated neural activity was observed in the posterior brain regions following the MVI programme. As the aim of the MVI programme was to emphasise the role of visual 
imagery in AM, we suggested that functional changes in the posterior brain regions that sustain MVI processes (Greenberg \& Rubin, 2003) would be observed. On the contrary, reduced functional connectivity was shown in the posterior brain regions in the experimental group after facilitation. While this finding seems counterintuitive, it is consistent with the neural efficiency hypothesis, which posits that greater neural involvement for task performance represents a less efficient use of neural resources (Grabner, Stern, \& Neubauer, 2003). This hypothesis has been put forward in previous studies in MS patients in which increased functional connectivity was associated with lower cognitive performance (Hawellek, Hipp, Lewis, Corbetta, \& Engel, 2011; Leavitt, Wylie, Genova, Chiaravalloti, \& DeLuca, 2012). In addition, since increased activation in the posterior brain regions was previously reported in association with AM impairment in MS patients (relative to healthy controls; Ernst et al., 2015), we suggest that the efficient use of the MVI strategy has led to a more efficient use of neural resources and, thus, to a decrease of the functional connectivity in these same brain areas after facilitation.

A positive association between AI score improvement and the volume of the left parahippocampal gyrus was documented in the experimental group. The involvement of the parahippocampal region in AM is well established (see Viard, Desgranges, Eustache, \& Piolino, 2012 for a review), with a particular role in contextual processing, in the generation of complex, coherent scenes, retrieval of visuo-spatial details, and recruitment of posterior brain regionsall of which fit with the MVI programme's aims.

Despite the absence of AM improvement, slight functional brain changes were observed in the control group. In particular, during the elaboration phase, enhanced brain activations and increased functional connectivity were observed in the lateral frontal regions following the control programme. Since the frontal lobe plays a role in the organisation of information (Lezak, Howieson, \& Loring, 2004) and that the control programme focused on the narrative structure and organisation of information, these brain activation changes could reflect the attempt to use 
the sham strategy, but with no clinical benefit on AM. The decreased activations observed in the medial frontal region during AM construction post-facilitation, in the control group, remain to be interpreted. Alternatively, these slight functional brain changes observed in the control group might also have been influenced by the increased recall of unique events during the fMRI task after the verbal control programme. However, a similar increase has been found in the experimental group and both groups provided an equivalent number of unique events in each session. As such, it is more likely that the increased number of unique events provided in postfacilitation in both groups reflects a practice effect, due to the fMRI task's repetition.

Some methodological limitations of this study should be mentioned. The first concerns the small sample size, which is related to the difficulty in constituting homogeneous, and thus comparable, groups of MS patients. However, a recent neuroimaging study supported the idea that large sample size in the context of cognitive interventions could also lead to misinterpretation of the results and that small samples and single-case studies are relevant in this line of research (Hubacher et al., 2015). A second limitation is the use of a liberal statistical threshold (note however that the threshold applied here has been frequently used in previous AM neuroimaging studies in healthy participants) and the current findings should thus be interpreted cautiously. However, our approach was to provide a complete overview of our findings in order to not overlook some neural landmarks (i.e., Type II error) that could be relevant for future investigations, especially in this underexplored line of research (see Lieberman \& Cunningham, 2009 for a review on Type I and Type II error concerns in fMRI research). Thus, we encourage the replication of the current findings in similar clinical settings. Third, and from a more clinical standpoint, we only included RR-MS patients leaving open the question of the effectiveness of this intervention in other MS subtypes. Finally, while the longterm robustness of clinical benefits of the MVI programme has been demonstrated (Ernst et al., 2015), long-term MRI measures also appear to be necessary. 
To our knowledge, this study is the first to document functional and structural brain changes following cognitive rehabilitation tackling AM in MS patients. To date, most of the cognitive rehabilitation studies conducted in MS patients (Chiaravalloti, Glenn, Leavitt, \& Deluca, 2012; Filippi et al., 2012; Leavitt et al., 2014; Parisi et al., 2014.; Penner et al., 2006) have only reported positive changes post-rehabilitation, namely increased brain activations or connectivity. In this context, our findings highlight that complex patterns of functional and structural changes could be associated with cognitive improvement and that signs of downregulated brain activity could also be associated with better cognitive performance.

In conclusion, this study demonstrated that AM, which plays a central role in daily life, could be efficiently improved in MS patients in a short timeframe and with a significant influence on brain functioning. We hope that these positive results could promote further studies aiming to develop new therapeutic interventions to enhance everyday life functioning of MS patients and will also encourage similar studies in other neurological or psychiatric conditions. In particular, exploring whether this intervention could be adapted in other clinical conditions presenting with decreased AM specificity, such as depression (Dalgleish et al., 2007; Williams et al., 2007), could represent a future avenue of research of clinical value and could further our understanding of the mechanisms that come into play between MVI and AM improvement.

\section{Acknowledgements}

We are grateful to the patients for their participation in this study. We thank the ARSEP foundation for research funding awarded to LM and the Ministry of National Education and Research (A.E.'s PhD grant) and the MRI Platform. AE is now a postdoctoral researcher at the University of Liege, funded by a Marie Curie COFUND fellowship. 
Published in NEUROPSYCHOLOGICAL REHABILITATION, 2016

http://dx.doi.org/10.1080/09602011.2016.1240697

\section{Disclosure statement}

No potential conflict of interest was reported by the authors.

\section{Funding}

This work was supported by the Fondation pour l'Aide à la Recherche sur la Sclérose en Plaques [grant number AO2006].

\section{References}


Addis, D. R., Wong, A. T., \& Schacter, D. L. (2007). Remembering the past and imagining the future: Common and distinct neural substrates during event construction and elaboration. Neuropsychologia, 45, 1363-1377.

Addis, D. R., Wong, A. T., \& Schacter, D. L. (2008). Age-related changes in the episodic simulation of future events. Psychological Science, 19, 33-41.

Andrews-Hanna, J. R., Reidler, J. S., Sepulcre, J., Poulin, R., \& Buckner, R. L. (2010). Functional-anatomic fractionation of the brain's default network. Neuron, 65, 550-562.

Axelrod, B. N., Ryan, J. J., \& Ward, L. C. (2001). Evaluation of seven-subtest short forms of the Wechsler Adult Intelligence Scale-III in a referred sample. Archives of Clinical Neuropsychology, 16, 1-8.

Bell, A. J., \& Sejnowski, T. J. (1995). An information-maximization approach to blind separation and blind deconvolution. Neural Computation, 7, 1129-1159.

Botzung, A., Denkova, E., Ciuciu, P., Scheiber, C., \& Manning, L. (2008). The neural bases of the constructive nature of autobiographical memories studied with a self-paced fMRI design. Memory, 16, 351-363.

Bourlon, C., Chokron, S., Bachoud-Lévi, A. C., Coubard, O., Bergeras, I., Moulignier, A., ... Bartolomeo, P. (2009). Presentation of an assessment battery for visual mental imagery and visual perception. Revue Neurologique, 165, 1045-1054. 
Burgess, P., \& Shallice, T. (1997). The Hayling and Brixton Tests. Test manual. Bury St Edmunds: Thames Valley Test Company.

Calhoun, V. D., Adali, T., Pearlson, G. D., \& Pekar, J. J. (2001). A method for making group inferences from functional MRI data using independent component analysis. Human Brain Mapping, 14, 140-151.

Chiaravalloti, N. D., \& DeLuca, J. (2008). Cognitive impairment in multiple sclerosis. The Lancet Neurology, 7, 1139-1151.

Chiaravalloti, N. D., Wylie, G., Leavitt, V., \& DeLuca, J. (2012). Increased cerebral activiation after behav-ioural treatment for memory deficits in MS. Journal of Neurology, 259(7), $1337-1343$.

Coughlan, A., \& Hollows, S. (1985). The Adult Memory and Information Processing Battery. Leeds: Saint James Hospital.

Crovitz, H. F., \& Schiffman, H. (1974). Frequency of episodic memories as a function of their age. Bulletin of the Psychonomic Society, 4, 517-518.

Dalgleish, T., Williams, J. M. G., Golden, A.-M. J., Perkins, N., Barrett, L. F., Barnard, P. J., ... Watkins, E. (2007). Reduced specificity of autobiographical memory and depression: 
The role of executive control. Journal of Experimental Psychology: General, 136, 2342.

Debouverie, M., Pittion-Vouyovitch, S., Louis, S., \& Guillemin, F. (2007). Validity of a French version of the fatigue impact scale in multiple sclerosis. Multiple Sclerosis Journal, 13, $1026-1032$.

Ernst, A., Blanc, F., De Seze, J., \& Manning, L. (2015). Using mental visual imagery to improve autobiographical memory and episodic future thinking in relapsing-remitting multiple sclerosis patients: A randomised-controlled trial study. Restorative Neurology and Neurosciences, 33, 621-638.

Ernst, A., Blanc, F., De Seze, J., Sellal, F., Chauvin, B., \& Manning, L. (2014). Impaired mental simulation of specific past and future personal events in non-depressed multiple sclerosis patients. Journal of the Neurological Sciences, 345, 68-74.

Ernst, A., Blanc, F., Voltzenlogel, V., de Seze, J., Chauvin, B., \& Manning, L. (2013). Autobiographical memory in multiple sclerosis patients: Assessment and cognitive facilitation. Neuropsychological Rehabilitation, 23, 161-181.

Ernst, A., Botzung, A., Gounot, D., Sellal, F., Blanc, F., de Seze, J., \& Manning, L. (2012). Induced brain plasticity after a facilitation programme for autobiographical memory in 
multiple sclerosis: A preliminary study. Multiple Sclerosis International, doi:10.1155/2012/820240

Ernst, A., Noblet, V., Denkova, E., Blanc, F., De Seze, J., Gounot, D., \& Manning, L. (2015). Functional cerebral changes in multiple sclerosis patients during an autobiographical memory test. Memory, 23, 1123- 1139.

Fastenau, P. S., Denburg, N. L., \& Hufford, B. J. (1999). Adult norms for the Rey-Osterrieth Complex Figure Test and for supplemental recognition and matching trials from the Extended Complex Figure Test. The Clinical Neuropsychologist (Neuropsychology, Development and Cognition: Section D), 13, 30-47.

Filippi, M., Riccitelli, G., Mattioli, F., Capra, R., Stampatori, C., Pagani, E., ... Rocca, M. A. (2012). Multiple sclerosis: Effects of cognitive rehabilitation on structural and functional MR imaging measures-An explorative study. Radiology, 262, 932-940.

Grabner, R. H., Stern, E., \& Neubauer, A. C. (2003). When intelligence loses its impact: Neural efficiency during reasoning in a familiar area. International Journal of Psychophysiology, 49, 89-98.

Greenberg, D. L., \& Rubin, D. C. (2003). The neuropsychology of autobiographical memory. Cortex, 39, 687-728.

Hart, T. (2009). Treatment definition in complex rehabilitation interventions. Neuropsychological Rehabilitation, 19, 824-840. 
Hawellek, D. J., Hipp, J. F., Lewis, C. M., Corbetta, M., \& Engel, A. K. (2011). Increased functional connectivity indicates the severity of cognitive impairment in multiple sclerosis. Proceedings of the National Academy of Sciences, 108, 19066-19071.

Himberg, J., Hyvärinen, A., \& Esposito, F. (2004). Validating the independent components of neuroimaging time series via clustering and visualization. NeuroImage, 22, 1214-1222.

Hubacher, M., Kappos, L., Weier, K., Stöcklin, M., Opwis, K., Penner, I.-K., \& Leavitt, V. M. (2015). Case-based fMRI analysis after cognitive rehabilitation in MS: A novel approach. Frontiers in Neurology, 6, 78. doi:10. 3389/fneur.2015.00078

Kremin, H. (2002). L'accès au lexique en dénomination d'images: problèmes actuels. Psychologie Française, 47, 77-91.

Kurtzke, J. F. (1983). Rating neurological impairment in multiple sclerosis: An Expanded Disability Status Scale (EDSS). Neurology, 33, 1444-1452.

Làdavass, E., Paolucci, S., \& Umiltà, C. (2011). Reasons for holding a consensus conference on neuropsy-chological rehabilitation in adult patients. European Journal of Physical and Rehabilitation Medicine, 47, 91-99.

Leavitt, V. M., Wylie, G., Genova, H. M., Chiaravalloti, N. D., \& DeLuca, J. (2012). Altered effective connectivity during performance of an information processing speed task in multiple sclerosis. Multiple Sclerosis Journal, 18, 409-417. 
Leavitt, V. M., Wylie, G. R., Girgis, P. A., Deluca, J., \& Chiaravalloti, N. D. (2014). Increased functional connectivity within memory networks following memory rehabilitation in multiple sclerosis. Brain Imaging and Behavior, 8, 394-402.

Levine, B., Svoboda, E., Hay, J. F., Winocur, G., \& Moscovitch, M. (2002). Aging and autobiographical memory: Dissociating episodic from semantic retrieval. Psychology and Aging, 17, 677-689.

Lezak, M. D., Howieson, D. B., \& Loring, D. W. (2004). Neuropsychological assessment (4th ed.). New York, NY: Oxford University Press.

Lieberman, M. D., \& Cunningham, W. A (2009). Type I and Type II error concerns in fMRI research: Rebalancing the scale. Social Cognitive and Affective Neuroscience, 4, 423428 .

Montgomery, S. A., \& Asberg, M. (1979). A new depression scale designed to be sensitive to change. The British Journal of Psychiatry, 134, 382-389.

Müller, S., Saur, R., Greve, B., Melms, A., Hautzinger, M., Fallgatter, A., \& Leyhe, T. (2013). Similar autobiographical memory impairment in long-term secondary progressive multiple sclerosis and Alzheimer's disease. Multiple Sclerosis Journal, 19, 225-232.

Northoff, G., Heinzel, A., de Greck, M., Bermpohl, F., Dobrowolny, H., \& Panksepp, J. (2006). Self-referential processing in our brain — A meta-analysis of imaging studies on the self. NeuroImage, 31, 440-457. 
Parisi, L., Rocca, M. A., Valsasina, P., Panicari, L., Mattioli, F., \& Filippi, M. (2014). Cognitive rehabilitation correlates with the functional connectivity of the anterior cingulate cortex in patients with multiple sclerosis. Brain Imaging and Behavior, 8, 387-393.

Penner, I. K., Kappos, L., Rausch, M., Opwis, K., \& Radü, E. W. (2006). Therapy-induced plasticity of cognitive functions in MS patients: Insights from fMRI. Journal of Physiology, 99, 455-462.

Polman, C. H., Reingold, S. C., Banwell, B., Clanet, M., Cohen, J. A., Filippi, M., .. Wolinsky, J. S. (2011). Diagnostic criteria for multiple sclerosis: 2010 revisions to the McDonald criteria. Annals of Neurology, 69, 292-302.

Rasmussen, A. S., \& Habermas, T. (2011). Factor structure of overall autobiographical memory usage: The directive, self and social functions revisited. Memory, 19, 597-605.

Raven, J. C. (1958). Advanced progressive matrices, Set 1. Manual. London: H. K. Lewis.

Rey, A. (1941). L'examen psychologique dans les cas d'encéphalopathie traumatique. Archives de Psychologie, 28, 286-340.

Rey, A. (1964). L'Examen clinique en Neuropsychologie. Paris: PUF.

Rubin, D. C., Schrauf, R. W., \& Greenberg, D. L. (2003). Belief and recollection of autobiographical memories. Memory \& Cognition, 31, 887-901. 
Shallice, T. (1982). Specific impairments of planning. Philosophical Transactions of the Royal Society B: Biological Sciences, 298, 199-209.

Shallice, T., \& Evans, M. E. (1978). The involvement of the frontal lobes in cognitive estimation. Cortex, 14, 294-303.

Strangman, G., O’Neil-Pirozzi, T. M., Burke, D., Cristina, D., Goldstein, R., Rauch, S. L., ... Glenn, M. B. (2005).Functional neuroimaging and cognitive rehabilitation for people with traumatic brain injury. American Journal of Physical Medicine \& Rehabilitation, $84,62-75$.

Stroop, J. R. (1935). Studies of interference in serial verbal reactions. Journal of Experimental Psychology, 18, 643-662.

Svoboda, E., McKinnon, M. C., \& Levine, B. (2006). The functional neuroanatomy of autobiographical memory: A meta-analysis. Neuropsychologia, 44, 2189-2208.

Talairach, J., \& Tournoux, P. (1988). Co-planar stereotaxic atlas of the human brain: 3dimensional proportional system. Stuttgart: Georg Thieme.

Tulving, E. (2002). Episodic memory: From mind to brain. Annual Review of Psychology, 53, $1-25$. 
Viard, A., Desgranges, B., Eustache, F., \& Piolino, P. (2012). Factors affecting medial temporal lobe engagement for past and future episodic events: An ALE meta-analysis of neuroimaging studies. Brain and Cognition, 80, 111-125.

Voltzenlogel, V., Desorés, O., Vignal, J. P., Steinhoff, B. J., Kehrli, P., \& Manning, L. (2006). Remote memory in temporal lobe epilepsy. Epilepsia, 47, 1329-1336.

Warrington, E., \& James, M. (1991). The Visual Object and Space Perception Battery (VOSP). Suffolk: Thames Valley Test Company.

Wechsler, D. (1997). Manual for the Wechsler Adult Intelligence Scale - Third Edition (WAISIII). San Antonio, TX: The Psychological Corporation.

Williams, J. M. G., Barnhofer, T., Crane, C., Herman, D., Raes, F., Watkins, E., ... Dalgleish, T. (2007). Autobiographical memory specificity and emotional disorder. Psychological Bulletin, 133, 122-148.

Wilson, B. A. (2009). Evidence for the effectiveness of neuropsychological rehabilitation. In B. A. Wilson, F. Gracey, J. J. Evans, \& A. Bateman (Eds.), Neuropsychological rehabilitation: Theory, models, therapy and outcome (pp. 22-36). New York: Cambridge University Press.

Wilson, B. A., \& Gracey, F. (2009). Towards a comprehensive model of neuropsychological rehabilitation. In B. A. Wilson, F. Gracey, J. J. Evans, \& A. Bateman (Eds.), 
Published in NEUROPSYCHOLOGICAL REHABILITATION, 2016

http://dx.doi.org/10.1080/09602011.2016.1240697

Neuropsychological rehabilitation: Theory, models, therapy and outcome (pp. 1-21).

New York: Cambridge University Press. 


\section{Appendix. Examples of pairs of words used during the AM fMRI task}

The French equivalent (used in this study) for each pair is indicated in brackets.

Birthday - Gift (Anniversaire - Cadeau)

Countryside - Sun (Campagne - Soleil)

Buying - Car (Achat - Voiture)

New Year's Eve dinner - Champagne (Réveillon - Champagne)

Baby - Cradle (Bébé - Berceau)

Reunion - Family (Retrouvailles - Famille)

Journey - Transport (Trajet - Transport)

Trip - Friend (Sortie - Ami)

First - Job (Premier - Emploi)

Costume - Carnival (Costume - Carnaval)

Lunch - Colleagues (Déjeuner - Collègues)

Store - Crowd (Magasin - Foule)

Trip - School (Sortie - Ecole)

Move - Box (Déménagement - Cartons)

Discovery - Admirer (Découverte - Admirer)

Letter - Important (Courrier - Important)

Market - Smell (Marché - Odeur)

Nature - Walk (Nature - Promenade)

Dinner - Candle (Dîner - Chandelle)

Holiday - Plane (Vacances - Avion) 